\title{
Recurrent Spontaneous Bilateral Subdural Hemorrhage as a Consequence of High-Cervical Spontaneous CSF Leak-Lessons for Neurosurgeons
}

\author{
Venugopal Subramaniam ${ }^{1} \quad$ Sibhi Ganapathy ${ }^{1, \odot}$ \\ ${ }^{1}$ Department of Neurosurgery, Manipal Hospital Whitefield, \\ Bangalore, Karnataka, India \\ 2Department of Anesthesiology, Manipal Hospital Whitefield, \\ Bangalore, Karnataka, India \\ ${ }^{3}$ Department of Radiodiagnostics, Manipal Hospital Whitefield, \\ Bangalore, Karnataka, India \\ Indian J Neurosurg 2021;1:6-12.
}

S. Shivananda ${ }^{2}$

K. N. Nagabhushan ${ }^{3}$

Raghu Murthy ${ }^{3}$

\author{
Address for correspondence Sibhi Ganapathy, MS, MCh, DNB, \\ MNAMS, FAGE, Department of Neurosurgery, Manipal Hospital \\ Whitefield, 13, Waterwoods, Ramagondanahalli, Varthur Road, \\ Bangalore 560066, Karnataka, India (e-mail: sibhig09@gmail.com).
}

\begin{abstract}
Keywords

- spontaneous

intracranial

hypotension

- recurrent subdural

hematomas

- bilateral subdural

hematomas

- spontaneous spinal

dural leaks

Spontaneous intracranial hypotension $(\mathrm{SIH})$ is rare. It presents as intractable posture headache and is identified by radiological findings. It is confirmed by cerebrospinal fluid (CSF) manometry and myelography, and treatment is carried out with the help of epidural blood patch (EBP) therapy. SIH presenting with spontaneous bilateral recurrent subdural bleeds is uncommon. The cause being a high-spinal CSF leak is even more uncommon! Our patient had recurrent bilateral spontaneous chronic subdural hematomas. Myelographic examination of the spine showed a C1-C2 level leak of CSF. He was taken up for open microsurgery, and the leak was identified and closed with fibrin glue. The patient however deteriorated the next day. An EBP was applied in the lumbar region to cover the myelogram lumbar puncture site. We present a review of literature and an algorithm to detect the elusive CSF leak and effect definitive treatment, either open or EBP, to treat the source of the problem.
\end{abstract}

\section{Key Message}

In the hustle of the emergency room, a diagnosis of chronic subdural bleeds, especially bilateral ones can imply immediate surgical evacuation. Such a course of action may be detrimental to the patient, as described below in our experience. Therefore, to prevent other neurosurgeons from reinventing the wheel, we present our own protocol for recurrent bilateral subdural hematomas to improve patient outcomes and reduce mistakes.

\section{Introduction}

Chronic subdural hemorrhage (CSDH) is a common surgical condition, owing to a collection of blood degradation products and plasma in the subdural space, which cause mass effect and midline shift inside the rigid calvarium..$^{1-4}$ [The procedure of making burrholes over the calvarium overlying the collection, opening the dura and drainage accompanied by lavage is widely acknowledged as an effective and simple strategy to effect good recovery. Bilateral CSDH (bCSDH) is infrequent but not uncommon due to the cerebral atrophy, leading to tension on the bridging veins of the subdural space and trivial trauma which may go unnoticed..$^{5-8}$ Recurrent CSDHs are also not uncommon as the subdural membrane can form, especially in the elderly and infirm, and persist despite repeated attempts at drainage. Craniotomy and membrane excision, instead of medical therapy such as calcium channel blockers, is widely acknowledged again as successful in treating this problem.

When one encounters recurrent bilateral chronic subdural hematomas, then the alarm bells ring as all procedures and medical therapies listed above fail to reduce recurrences and morbidity among the patients. ${ }^{9,10,11}$ Investigation of deeper and more sinister causes like coagulation abnormalities, hematological malignancies, and dural vascular malformations,
DOI https://doi.org/ $10.1055 / \mathrm{s}-0040-1721203$ ISSN 2277-954X.
(C) 2021. Neurological Surgeons' Society of India.

This is an open access article published by Thieme under the terms of the Creative Commons Attribution-NonDerivative-NonCommercial-License, permitting copying and reproduction so long as the original work is given appropriate credit. Contents may not be used for commercial purposes, or adapted, remixed, transformed or built upon. (https://creativecommons.org/licenses/by-nc-nd/4.0/)

Thieme Medical and Scientific Publishers Pvt. Ltd., A-12, 2nd Floor, Sector 2, Noida-201301 UP, India 
although pertinent, would have been detected earlier in the preoperative workup itself. Thus, recurrent bCSDHs are difficult to manage, as the root cause often remains obscure. Such a disease is spontaneous intracranial hypotension (SIH). ${ }^{12,13}$

$\mathrm{SIH}$ has been known for many decades and is acknowledged to contribute to postural headaches usually without the history of trauma, which succeed lumbar puncture of spinal dural trauma. Most of these patients eventually recover with abdominal binders, epidural blood patch (EBP)therapy, caffeine and analgesics. Recalcitrant SIH is a novelty reported in a handful of reports. SIH leading to bilateral CSDHs while reported in literature are noted to be the rarest of rare presentations for this rare disease. Recurrent bCSDHs due to this phenomenon and presenting with decreased sensorium without significant headache is noteworthy, since it changes the management protocol and is not reported elsewhere to our knowledge. ${ }^{14-17}$

We present the case report, where a surgical perspective is offered to what started off as a purely surgical situation, but morphed into a complex series of events which threatened to cause major problems to the patient. Timely intervention led to the detection and rescue of the situation, leading to an ultimately positive outcome for the patient. The series of events however made us extensively analyze our own attempt as well as published literature for answers regarding faster and perhaps less traumatic algorithms for the detection and treatment of this disease. The result was our own protocol, which we feel helps to shorten the diagnostic time and ease the dilemma in treating such disorders. We present both the case report and its discussion and analysis below.

\section{Case Report}

A 50-year-old male patient, who presented with progressive drowsiness without significant headache, was diagnosed to have bCSDH. After a usual preoperative checkup which included brain MRI and CT imaging, he was slated for surgery the next day, but a rapid deterioration occurred over the course of the night with a drop in Glasgow coma scale (GCS) score and urinary incontinence. He was therefore taken up for emergency surgery, and bilateral frontal and parietal burrholes with lavage and evacuation of the bCSDH was done. No subdural membrane was seen, and the brain surfaced well immediately after decompression. The subdural bleeds were under moderate pressure and egressed quickly on opening of the dura. Immediately after surgery, the patient was alert and pain-free. He was discharged in 2 days on antiepileptics and antibiotics.

The same patient was back after 2 weeks with altered sensorium but no headache. A scan revealed a mild residual subdural hematoma and pneumocephalus. It was presumed that the recollection with tension pneumocephalus had led to a raise in intracranial pressure (ICP), causing the symptoms. Hence, after explaining the risks, he was taken up for a repeat drainage and lavage. As a membrane was suspected, a minicraniotomy was done, and the subdural membrane was excised. The membrane was not thick or vascular but was found to be in the early stages of formation. Despite these findings, the procedure was completed in good faith, and the patient was shifted to recovery. Immediately postop, he was alert and conscious, but his sensorium gradually deteriorated the next day. The peculiar aspect of this deterioration was the complete absence of any significant associated headaches at all, although urinary incontinence was present.

Another CT scan showed pneumocephalus with a small remnant of the subdural collections present. The pneumocephalus was not massive enough to cause tension but seemed to cause compression of the brain. No hyponatremia, hyperglycemia or metabolic and endocrine causes of sensorium fluctuation were seen. Due to the diffuse brain edema and accompanying pneumocephalus, and as a desperate attempt to decompress what was considered a high ICP situation, a bilateral decompressive craniectomy was done. This time the patient did not improve postsurgery, and repeat imaging showed persistent pneumocephalus.

The persistent pneumocephalus along with no improvement in sensorium despite all decompressive measures, and normal metabolic parameters, made us suspect other pathologies. The patient was subjected to a CT myelogram. The early films did not show any abnormality, but a delayed sequence showed a large lateral cerebrospinal fluid (CSF) leak at the C1-C2 level ( - Fig. 1). Hence, the patient was diagnosed with spontaneous intracranial hypotension, and was taken up for an EBP. As the spinal needle was placed into the C7 space, the patient went into a sudden episode of bradycardia, leading to hypotension. The procedure was immediately abandoned, and the patient was successfully resuscitated.

Due to the unstable nature of the disease, along with the risk of herniation through the foramen magnum, the patient was taken up after stabilization for a C2 laminectomy and leak occlusion using fibrin glue. The patient was placed under general anesthesia with an arterial line to monitor blood pressure, carefully monitored, and placed prone with head in flexion. A $5 \mathrm{~cm}$ linear vertical incision was made in the midline and the $\mathrm{C} 2$ lamina was dissected out. A C2 laminectomy and fenestration of the C1 were performed. Large venous malformations were seen on the left side just adjacent to the $\mathrm{C} 2$ lamina. The veins were examined, and the leak was detected. Fibrin glue was generously placed all

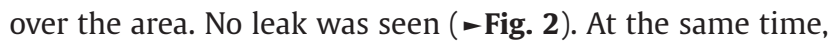
a bilateral titanium mesh cranioplasty was done to cover the open calvarial defects and ensure the pressure differential was reduced, enabling recalibration of ICP and expedient normalizing of symptoms. The patient was shifted on tube

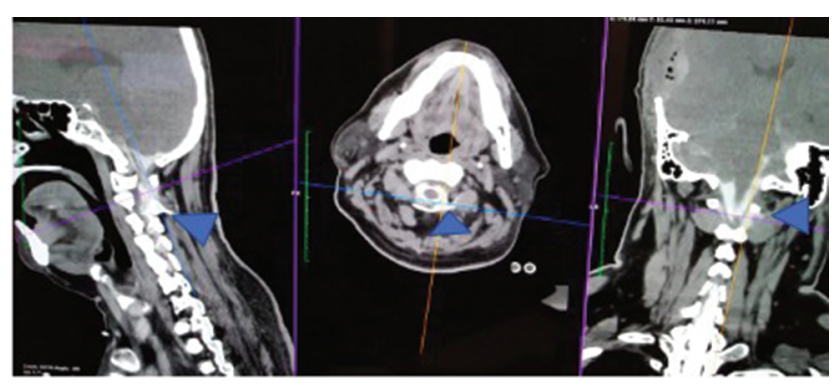

Fig. 1 Myelography delayed images in sagittal, axial, and coronal views, demonstrating the egress of contrast and confirming the presence of a leak. 


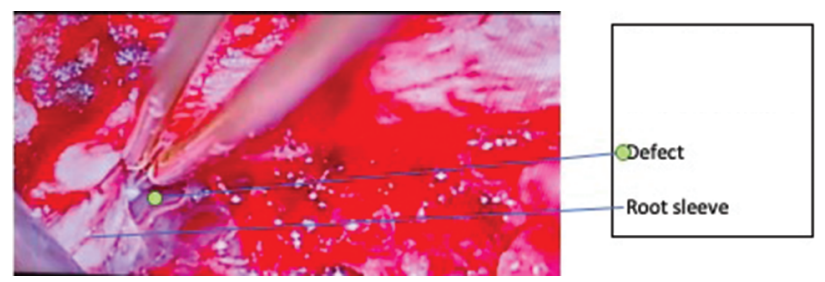

Fig. 2 A large dural defect on the left C2 root sleeve.

under sedation and placed in intensive care. His sedation was removed after 12 hours, and he was extubated. He showed significant improvement, was eventually shifted out of the ICU to the ward and mobilized.

To ensure documentation of the repair and confirm the treatment efficacy before discharge, the myelogram was repeated to show the occlusion of the leak. The myelogram showed admirable occlusion of the leak, suggesting complete success of the open procedure. However, after the myelogram, the patient showed sudden and drastic deterioration of sensorium. Another round of investigations showed a recurrence of pneumocephalus with cerebral edema. We concluded that the lumbar puncture from the myelogram might have led to another CSF leak, perpetuating the hypotension. Hence, an EBP was applied at the lumbar region above the site of the myelogram. The patient improved remarkably and was able to walk without support within 12 hours, awake, and alert, as he was responding normally to stimuli.

The patient was discharged to review in OPD. He was slated for a detailed investigation of possible collagen vascular disorders such as Ehler-Danlos syndrome or Marfan at a later date, allowing him to recover from his ordeal. He was seen 2 months later in OPD, showing complete recovery with no recurrence of the bCSDH for which he initially visited the hospital. The tests for connective tissue disorders are ongoing, and therefore the cause of his extremely pressure-sensitive and fragile dura remains to be detected.

\section{Discussion}

\section{Spontaneous Intracranial Hypotension}

Spontaneous Intracranial Hypotension ( $\mathrm{SIH})$, as the name implies, is caused by low CSF pressure, usually secondary to an occult leak..$^{1718}$ Occasional damage to the dura occurs due to tears caused by osteophytes protruding into the canal or around the nerve sheaths. Some studies have reported that connective tissue disorders such as Marfan syndrome, Ehlers-Danlos syndrome type 2, and autosomal dominant polycystic kidney disease play a significant role in causing $\mathrm{SIH}^{18-20}$

While the pathophysiology of SDH in patients with SIH remains unknown, studies have proposed several mechanisms..$^{20-23}$ Downward displacement of the brain due to low CSF pressure may produce tears in the bridging veins of the dural border cell layer, causing these veins to rupture. Alternatively, as subdural CSF collections gradually enlarge the subdural space, the bridging veins may stretch and rupture in some cases.

Although the most common presenting symptom in $\mathrm{SIH}$ is orthostatic headaches, the presentation of bCSDH without significant postural headaches requires careful assessment of the pathology. ${ }^{23}$ Although the SIH induced bCSDH is due to the stretch on the bridging veins secondary to spinal CSF egress, unusual clinical variation should prompt for more imaging. ${ }^{24,25}$

\section{Radiology}

MR imaging represents the method of choice to depict intracranial manifestations; the neuroimaging features include diffuse meningeal enhancement, acquired Chiari malformation, and subdural fluid collections. ${ }^{23-25}$ The Monro-Kellie hypothesis is the mechanism frequently used to explain MRI findings with aforementioned conditions. ${ }^{23,24} \mathrm{~A}$ reduction in the volume of the CSF requires an increase in volume of one or both of the other components. The most reliably demonstrated area of increased volume on imaging is the pachymeninges, which show diffuse thickening and enhancement with gadolinium-enhanced MRI due to lack of a blood-brain barrier and an increase in the volume of venous blood in this compartment. ${ }^{24,25}$ In cases of SIH, the site of the CSF leak rests predominantly in the cervical or thoracic region, and the diagnosis is typically established by CT myelography or radionuclide imaging. ${ }^{25}$

In our patient, CT myelography was instrumental in identifying the leak site. But the difficulty was in suspecting such a leak in the first place, where such MR features were absent and the deteriorating patient condition with recollecting subdural collections and pneumocephalus suggested unusual origins. ${ }^{24,25}$

Although supportive measures and medical therapy such as hydration, bed rest, caffeine, steroid, and parenteral fluid may provide temporary relief, a more durable treatment is to seal the site of the leak. The mainstay of the treatment is the injection of autologous blood $(10-20 \mathrm{~mL})$ into the spinal epidural space. Relief of symptoms is often dramatic after EBP. If EBP fails the first time, it can be repeated. Complications of cervical EBP include spinal cord and nerve root compression, chemical meningitis, intrathecal injection of blood, seizures, and stiffness of the neck. ${ }^{24,25 .}$

\section{High-Cervical Dural Leaks}

Cases of large subdural hemorrhage require surgical drainage and treatment of the underlying cause of SIH. ${ }^{25}$ With the current technology, we can perform imaging-guided procedures in the spine with relative safety and minimal discomfort to the patient. In cases of cervical leaks, it is reasonable to offer a cervical blood patch as the initial treatment. ${ }^{25}$ The problem is when patients have high-cervical fistulae. This makes blood patch placement dangerous. Experienced anesthetists or pain specialists who are well-versed in cisternal puncture may attempt the procedure. There are anecdotes of epidural catheters advanced under $\mathrm{C}$-arm guidance from $\mathrm{C} 7$ upward to the craniovertebral (CV) junction for EBP placement. Such procedures are risky and are associated with frequent vasovagal attacks due to the high-concentration sympathetic nerves present in the upper cervical region. ${ }^{24,25}$ Such an episode occurred with our patient, which emphasized the danger of this approach. Some reports have suggested an EBP delivered at $\mathrm{C} 7$ and the patient placed in Trendelenburg position for variable periods of time to allow the blood to trickle down 
to the $\mathrm{CV}$ junction and block the leak. Such an approach was unacceptable to us, as we felt it was unreliable and vague. ${ }^{25-27}$

The deteriorating condition of our patient also emphasized the need for urgent and successful intervention. Thus, microsurgery was planned, and under vision, the leak was sealed with fibrin glue. Spontaneous epidural leaks, especially in the cervical region, are reported to be in close proximity to large engorged venous channels. ${ }^{27,28}$ Locating such channels and looking in their vicinity enable detection of the leak; during surgery, Valsalva maneuvers were not done, owing to the propensity of the pressure difference to worsen the hypotension and thereby effect tonsillar herniation. Thus, the venous channels are vital in identifying the leak. ${ }^{28,29} \mathrm{~A}$ generous application of fibrin glue all around the leak helped completely seal the rent. The patient was not extubated postsurgery. He was shifted to the ICU and slowly extubated. Postop, he improved rapidly.

\section{Recurrent Dural Leaks at Different Levels}

Recurrent SIH due to different dural rents and leaks is extremely rare. ${ }^{29}$ Hence, to confirm the efficacy of the surgery, myelogram was repeated. The SIH created by the lumbar puncture was unexpected and astonishing. Pressure sensitive dura of this nature has not been reported. Such as it was, the sealing of the rent resulted almost instantaneous improvement. The absence of any reported literature or explanation for this phenomenon remains a cause of concern. In the past 20 years, the reports of SIH with recurrent SDHs which underwent successful treatment are listed below. ${ }^{29}$ But many cases have been diagnosed retrospectively upon nonimprovement of symptoms or frank deterioration after surgery. The sheer numbers and the difficult nature of diagnosis in this scenario makes it necessary to devise a protocol for quick diagnosis and treatment (-Table $\mathbf{1}$ ).

Table 1 Reports of spontaneous intracranial hypotension presenting as recurrent bilateral chronic subdural hematomas in the past 20 years from 2000 to 2020

\begin{tabular}{|c|c|c|c|}
\hline S. No. & Study & $\begin{array}{l}\text { Year of } \\
\text { publication }\end{array}$ & Journal \\
\hline 1. & $\begin{array}{l}\text { Mikawa S, Ebina T. [Spontaneous intracranial hypotension } \\
\text { complicating subdural hematoma: unilateral oculomotor nerve } \\
\text { palsy caused by epidural blood patch]. No Shinkei Geka 2001; } \\
\text { 29(8):747-753 }\end{array}$ & 2001 & No Shinkei Geka \\
\hline 2. & $\begin{array}{l}\text { Murakami M, Morikawa K, Matsuno A, Kaneda K, Nagashima T. } \\
\text { Spontaneous intracranial hypotension associated with bilateral } \\
\text { chronic subdural hematomas--case report. Neurol Med Chir } \\
\text { (Tokyo) 2000; 40(9):484-488 }\end{array}$ & 2000 & $\begin{array}{l}\text { Neurological Medicine } \\
\text { and Chirugery }\end{array}$ \\
\hline 3. & $\begin{array}{l}\text { Kim MO, Kim J, Kang J, et al. Spontaneous intracranial hypotension } \\
\text { as a cause of subdural hematoma in a patient with cerebral } \\
\text { venous thrombosis on anticoagulation treatment. J Clin Neurol } \\
\text { 2020; 16(2):327-329 }\end{array}$ & 2020 & $\begin{array}{l}\text { Journal of Clinical } \\
\text { Neurology }\end{array}$ \\
\hline 4. & $\begin{array}{l}\text { Shin HS, Lee SH, Ko HC, Koh JS. Extended pneumocephalus } \\
\text { after drainage of chronic subdural hematoma associated with } \\
\text { intracranial hypotension: case report with pathophysiologic } \\
\text { consideration. J Korean Neurosurg Soc 2016; 59(1):69-74 }\end{array}$ & 2016 & $\begin{array}{l}\text { Journal of Korean } \\
\text { Neurosurgery Ssociety }\end{array}$ \\
\hline 5. & $\begin{array}{l}\text { Takahashi K, Mima T, Akiba Y. Chronic subdural hematoma } \\
\text { associated with spontaneous intracranial hypotension: therapeu- } \\
\text { tic strategies and outcomes of } 55 \text { cases. Neurol Med Chir (Tokyo) } \\
\text { 2016; 56(2):69-76 }\end{array}$ & 2016 & $\begin{array}{l}\text { Neurological Medicine } \\
\text { and Chirugery }\end{array}$ \\
\hline 6. & $\begin{array}{l}\text { Platz J, Glücker T, Gratzl O, Woydt M. Spontaneous intracranial } \\
\text { hypotension: case report with subdural hematomas, steroid } \\
\text { dependency and clinical improvement after myelography. } \\
\text { Zentralbl Neurochir 2007; 68(2):87-90 }\end{array}$ & 2007 & Zentralbl Neurochirugy \\
\hline 7. & $\begin{array}{l}\text { Takahashi T, Senbokuya N, Horikoshi T, Sato E, Nukui H, Kinouchi } \\
\text { H. [Refractory chronic subdural hematoma due to spontaneous } \\
\text { intracranial hypotension]. No Shinkei Geka 2007; 35(8):799-806 }\end{array}$ & 2007 & No Shinkei Geka \\
\hline 8. & $\begin{array}{l}\text { Su CS, Lan MY, Chang YY, Lin WC, Liu KT. Clinical features, } \\
\text { neuroimaging and treatment of spontaneous intracranial } \\
\text { hypotension and magnetic resonance imaging evidence of blind } \\
\text { epidural blood patch. Eur Neurol 2009; 61(5):301-307 }\end{array}$ & 2009 & $\begin{array}{l}\text { European Journal of } \\
\text { Neurology }\end{array}$ \\
\hline 9. & $\begin{array}{l}\text { Zhang J, Jin D, Pan KH. Epidural blood patch for spontaneous } \\
\text { intracranial hypotension with chronic subdural haematoma: a case } \\
\text { report and literature review. J Int Med Res 2016; 44(4):976-981 }\end{array}$ & 2016 & $\begin{array}{l}\text { Journal of Internal } \\
\text { Medicine Residents }\end{array}$ \\
\hline
\end{tabular}


Table 1 (continued)

\begin{tabular}{|c|c|c|c|}
\hline S. No. & Study & $\begin{array}{l}\text { Year of } \\
\text { publication }\end{array}$ & Journal \\
\hline 10. & $\begin{array}{l}\text { Mikawa S, Ebina T. [Spontaneous intracranial hypotension complicating } \\
\text { subdural hematoma: unilateral oculomotor nerve palsy caused by } \\
\text { epidural blood patch]. No Shinkei Geka 2001; 29(8):747-753 }\end{array}$ & 2001 & No Shinkei Geka \\
\hline 11. & $\begin{array}{l}\text { Rettenmaier LA, Park BJ, Holland MT, et al. Value of targeted } \\
\text { epidural blood patch and management of subdural hematoma in } \\
\text { spontaneous intracranial hypotension: case report and review of } \\
\text { the literature. World Neurosurg 2017; } 97: 27-38\end{array}$ & 2017 & World Neurosurgery \\
\hline 12. & $\begin{array}{l}\text { Wang HK, Liliang PC, Liang CL, Lu K, Hung KC, Chen HJ. Delayed } \\
\text { subdural hematoma after epidural blood patching in a patient } \\
\text { with spontaneous intracranial hypotension--case report. Neurol } \\
\text { Med Chir (Tokyo) 2010; 50(6):479-481 }\end{array}$ & 2010 & $\begin{array}{l}\text { Neurological Medicine } \\
\text { and Chirugery }\end{array}$ \\
\hline 13. & $\begin{array}{l}\text { Lai TH, Fuh JL, Lirng JF, Tsai PH, Wang SJ. Subdural haematoma in } \\
\text { patients with spontaneous intracranial hypotension. Cephalalgia } \\
\text { 2007; } 27(2): 133-138\end{array}$ & 2007 & Cephalgia \\
\hline 14. & $\begin{array}{l}\text { Chen YC, Wang YF, Li JY, et al. Treatment and prognosis of subdural } \\
\text { hematoma in patients with spontaneous intracranial hypotension. } \\
\text { Cephalalgia 2016; 36(3):225-231 }\end{array}$ & 2016 & Cephalgia \\
\hline 15. & $\begin{array}{l}\text { Schievink WI. Spontaneous spinal cerebrospinal fluid leaks and } \\
\text { intracranial hypotension. JAMA 2006; 295(19):2286-2296 }\end{array}$ & 2006 & JAMA \\
\hline 16. & $\begin{array}{l}\text { Zhang D, Wang J, Zhang Q, He F, Hu X. Cerebral venous thrombosis } \\
\text { in spontaneous intracranial hypotension: a report on } 4 \text { cases and a } \\
\text { review of the literature. Headache } 2018 ; 58(8): 1244-1255\end{array}$ & 2018 & Headache \\
\hline
\end{tabular}

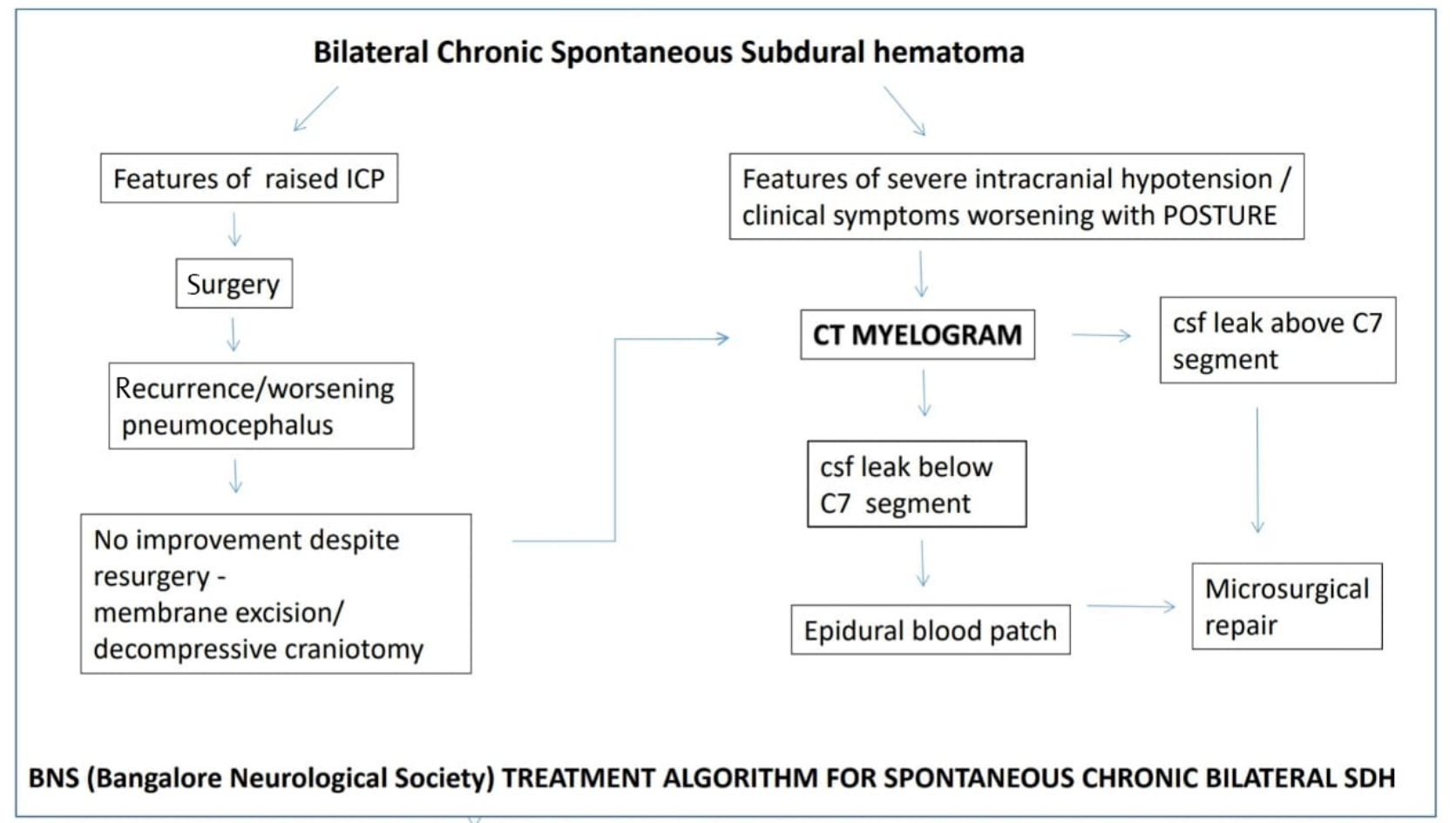

Fig. 3 The BNS protocol for management of spontaneous intracranial hypotension presentng as bilateral recurrent chronic subdural hemorrhage. ICP, intracranial pressure.

\section{Bangalore Neurological Society Protocol (BNS) for Recurrent Bilateral Subdural Bleeds}

Therefore, in an attempt to standardize the management of this rare and puzzling disease, we, from the point of neurosurgeons, wish to offer our own diagnostic protocol to prevent reinventing the wheel every time a patient presents with such symptoms, thereby saving time, hospital stay and agony all around. Our BNS protocol begins from the stage of bilateral recurrent subdural bleeds, which is seen occasionally in neurosurgery outpatient clinics and emergency rooms. The progress to decide on intervention proceeds as shown in - Fig. $\mathbf{3}$. 
When patients present with bilateral subdural bleeds, rather than immediately proposing surgery, an MRI is advised to rule out features of SIH. MRIs are particularly important as clinical features of raised and low ICT may overlap. In the absence of such features, the collections maybe evacuated. But a recurrence of collections, low sensorium, worsening pneumocephalus, and an absence of a subdural membrane should always point toward a spinal dural leak. Myelography is diagnostic, and management is done as discussed. Recurrence is very rare, but possible. Hence, a keen eye must be kept for dip in sensorium. A longer than expected stay in the hospital under observation is recommended to ensure no delayed deterioration occurs. Fortunately, recurrent spontaneous leaks are unheard of; thus, follow-ups are generally an uneventful for both patient and neurosurgeon alike.

\section{Red Flags to Suspected SIH}

1. Classical postural headache.

2. Worsening of bCSDHs/sensorium in erect position.

3. Postdural puncture headache (strong correlation).

4. Postspinal anesthesia subdural bleeds.

5. Postdural puncture cranial nerve palsy.

\section{Conclusion}

$\mathrm{SIH}$ is a rare chameleon which may mimic the simplest of neurosurgical emergencies. A keen understanding of intracranial pressure dynamics will assist in diagnosis and early management of this difficult disease. The BNS protocol suggested by us helps to reduce trial and error, thereby improving patient outcomes and reducing hospital stay simultaneously.

\section{Funding}

None.

\section{Conflict of Interest}

None declared.

\section{References}

1 Amorim JA, Remígio DS, Damázio Filho O, de Barros MA, Carvalho VN, Valença MM. Intracranial subdural hematoma post-spinal anesthesia: report of two cases and review of 33 cases in the literature. Rev Bras Anestesiol 2010;60(6):620-629, 344-349

2 Beier AD, Soo TM, Claybrooks R. Subdural hematoma after microdiscectomy: a case report and review of the literature. Spine J 2009;9(10):e9-e12

3 Cohen-Gadol AA, Mokri B, Piepgras DG, Meyer FB, Atkinson JL. Surgical anatomy of dural defects in spontaneous spinal cerebrospinal fluid leaks. Neurosurgery 2006;58(4, Suppl 2): ONS-238-ONS-245, discussion ONS-245

4 Forster MT, Mathé AK, Senft C, Scharrer I, Seifert V, Gerlach R. The influence of preoperative anticoagulation on outcome and quality of life after surgical treatment of chronic subdural hematoma. J Clin Neurosci 2010;17(8): 975-979

5 Gardner WJ. Traumatic subdural hematoma: with particular reference to the latenl interval. Arch Neurol Psychiatry 1932;27:847-858

6 Gaucher DJ, Jr, Perez JA, Jr. Subdural hematoma following lumbar puncture. Arch Intern Med 2002;162(16):1904-1905

7 Ishihara H, Ishihara S, Kohyama S, et al. Experience in endovascular treatment of recurrent chronic subdural hematoma. Interv Neuroradiol 2007;13(Suppl 1) :141-144

8 Ko BS, Lee JK, Seo BR, Moon SJ, Kim JH, Kim SH. Clinical analysis of risk factors related to recurrent chronic subdural hematoma. J Korean Neurosurg Soc 2008;43(1):11-15

9 Langdown AJ, Grundy JR, Birch NC. The clinical relevance of Tarlov cysts. J Spinal Disord Tech 2005;18(1):29-33

10 Markwalder TM. Chronic subdural hematomas: a review. J Neurosurg 1981;54(5):637-645

11 Mori K, Maeda M. Risk factors for the occurrence of chronic subdural haematomas after neurosurgical procedures. Acta Neurochir (Wien) 2003;145(7):533-539, discussion 539-540

12 Mori K, Maeda M. Surgical treatment of chronic subdural hematoma in 500 consecutive cases: clinical characteristics, surgical outcome, complications, and recurrence rate. Neurol Med Chir (Tokyo) 2001;41(8):371-381

13 Oishi M, Toyama M, Tamatani S, Kitazawa T, Saito M. Clinical factors of recurrent chronic subdural hematoma. Neurol Med Chir (Tokyo) 2001;41(8):382-386

14 Putnam TJ, Cushing H. Chronic subdural hematoma: its pathology, its relation to pachymeningitis hemorrhagica and its surgical treatment. Arch Surg 1925;11:329-393

15 Buvanendran A, Byrne RW, Kari M, Kroin JS. Occult cervical (C1-2) dural tear causing bilateral recurrent subdural hematomas and repaired with cervical epidural blood patch. J Neurosurg Spine 2008;9(5):483-487

16 Chen HH, Huang CI, Hseu SS, Lirng JF. Bilateral subdural hematomas caused by spontaneous intracranial hypotension. J Chin Med Assoc 2008;71(3):147-151

17 Cousins MJ, Brazier D, Cook R. Intracranial hypotension caused by cervical cerebrospinal fluid leak: treatment with epidural blood patch. Anesth Analg 2004;98(6):1794-1797

18 Dillo W, Hollenhorst J, Brassel F. von Hof-Strobach K, Heidenreich F, Johannes S. Successful treatment of a spontaneous cervical cerebrospinal fluid leak with a CT guided epidural blood patch. J Neurol 2002;249(2):224-225

19 Fishman RA, Dillon WP. Dural enhancement and cerebral displacement secondary to intracranial hypotension. Neurology 1993;43(3 Pt 1) :609-611

20 Inamasu J, Nakatsukasa M. Blood patch for spontaneous intracranial hypotension caused by cerebrospinal fluid leak at C1-2. Clin Neurol Neurosurg 2007;109(8):716-719

21 Mokri B. The Monro-Kellie hypothesis: applications in CSF volume depletion. Neurology 2001;56(12):1746-1748

22 Mokri B, Maher CO, Sencakova D. Spontaneous CSF leaks: underlying disorder of connective tissue. Neurology 2002; 58(5):814-816

23 Nardone R, Caleri F, Golaszewski S, et al. Subdural hematoma in a patient with spontaneous intracranial hypotension and cerebral venous thrombosis. Neurol Sci 2010;31(5): 669-672

24 Pannullo SC, Reich JB, Krol G, Deck MD, Posner JB. MRI changes in intracranial hypotension. Neurology 1993;43(5):919-926 
12 Recurrent Spontaneous Bilateral Subdural Hemorrhage Subramaniam et al.

25 Rando TA, Fishman RA. Spontaneous intracranial hypotension: report of two cases and review of the literature. Neurology 1992;42(3 Pt 1) :481-487

26 Rai A, Rosen C, Carpenter J, Miele V. Epidural blood patch at C2: diagnosis and treatment of spontaneous intracranial hypotension. AJNR Am J Neuroradiol 2005;26(10):2663-2666

27 Schievink WI. Spontaneous spinal cerebrospinal fluid leaks and intracranial hypotension. JAMA 2006;295(19):2286-2296
28 Vaidhyanath R, Kenningham R, Khan A, Messios N. Spontaneous intracranial hypotension: a cause of severe acute headache. Emerg Med J 2007;24(10):739-741

29 Bousser MG. [Headache in spontaneous cerebrospinal fluid hypotension]. Rev Neurol (Paris) 2005;161(6-7):700-702 